\title{
Effect of POSS Particles and Synergism Action of POSS and Poly-(Melamine Phosphate) on the Thermal Properties and Flame Retardance of Silicone Rubber Composites
}

\author{
Przemysław Rybiński ${ }^{1, *(1)}$, Bartłomiej Syrek ${ }^{1}$, Dariusz Bradło ${ }^{2}$ and Witold Żukowski ${ }^{2}$ \\ 1 Faculty of Mathematics and Natural Science, Jan Kochanowski University, Świętokrzyska 15, \\ Kielce 25-406, Poland; bartlomiejsyrek@wp.pl \\ 2 Faculty of Chemical Engineering and Technology, Cracow University of Technology, Warszawska 24, \\ Cracow 31-155, Poland; dariusz.bradlo@gmail.com (D.B.); pczukows@gmail.com (W.Ż.) \\ * Correspondence: przemyslaw.rybinski@ujk.edu.pl
}

Received: 25 June 2018; Accepted: 24 July 2018; Published: 27 July 2018

\begin{abstract}
This article presents flame retardant compounds for silicone rubber (SR) in the form of polyhedral oligomeric silsequioxanes (POSS), containing both isobutyl groups and amino-propyl (AM-POSS) or chloro-propyl group (HA-POSS) or vinyl groups (OL-POSS). Silsequioxanes were incorporated into the silicone rubber matrix in a quantity of 3 and 6 parts by wt by the method of reactive stirring with the use of a laboratory mixing mill. Based on the analyses performed by TG (Thermogravimetry) FTIR (Fourier Transform Infrared Spectroscopy), conical calorimeter, and SEM-EDX (Scanning Electron Microscopy and Energy Dispersive X-ray Spectroscopy) methods, the thermal degradation mechanism of non-cross-linked and cross-linked silicone rubber has been elucidated. The effects of POSS, and POSS in a synergic system with melamine polyphosphate (MPP), on the thermal properties and flammability of silicone rubber composites were presented. Based on the test results obtained, a mechanism of flame retardant action POSS and POSS-MPP has been proposed. It has been shown that POSS, especially with MPP, considerably increases the thermal stability and decreases the flammability of the SR rubber composites under investigation.
\end{abstract}

Keywords: silicone rubber; polyhedral oligomeric silsesquioxanes (POSS); melamine polyphosphate; thermal properties; flammability

\section{Introduction}

Silicone rubbers (SR) are characterized by excellent compatibility, and chemical, thermal, and UV resistances, and also showing very good dielectric properties. Unfortunately, silicone rubbers are flammable polymers; when ignited they are totally burnt, releasing great amounts of heat within a short period of time. The flammability of silicone rubbers considerably reduces their use in the medical, automotive, power, and cable industries [1,2].

A commonly used method of improving the resistance of polymeric materials, including silicone rubbers, against the action of fire consists of incorporating additive flame-resistant compounds into their matrix. On account of environmental restrictions concerning the use of halogen flame retardants, at present halogen-free organophosphorus flame-retardant compounds, such as melamine polyphosphate (MPP) or ammonium polyphosphate (APP), have the greatest application potential [3].

The action of organophosphorus compounds consists in forming an expanded, intumescent carbon layer on the polymer surface during its thermal decomposition. This layer acts as a barrier preventing heat transfer from its source to the polymer surface and reducing the fuel transfer to the flame [4]. 
To obtain a high efficiency of flame retardant compounds, one has to incorporate them into the polymeric matrix in the presence of carbon-rich compounds.

During the thermal decomposition of a polymeric composite, the organophosphorus compounds contained in it, e.g., MPP, undergo degradation to water, ammonia, and PP acid that when reacting with carbon compounds, forms thermally unstable esters of phosphoric acid. Their decomposition, mainly by dehydration processes, results in the formation of a carbon layer cutting off the flow of oxygen, fuel, and heat between the polymer and flame. Water vapor and nitrogen compounds formed during the MPP decomposition diffusing to the flame, foam the liquid destruction products of the composite and increase the insulating power of the boundary layer [5].

The incorporation of MPP into the poor in carbon silicone rubber to make it flame retardant must be combined with a carbonizing additive, such as pentaerythritol (PER) [6].

From the investigations performed so far, it distinctly follows that the satisfactory effectiveness of the MPP/PER system, especially in relation to silicone rubber, can be obtained when its content is over 30 parts by wt. Unfortunately, such a high quantity of this flame retardant negatively affects the processing, functional properties, and price of the silicone rubber composites obtained [7].

New, alternative of halogen and halogen-free flame-retardant compounds are polyhedral oligomeric silsequioxanes (POSS) [8,9]. POSS have the structure of cage whose edges are built of combined silicone and oxygen atoms. Organic ligands are directly linked to silicon atoms, owing to which, the cage can be combined with polymer chains by means of covalent bonds, forming hybrid composites. The size of silicate cages ranges from 1 to $3 \mathrm{~nm}$, hence they are treated as the smallest silica particles to be obtained [10].

POSS can be incorporated as reactive components during polymerization or combined with macromolecules by their direct plasticization with the polymeric matrix.

From the investigations performed so far, it follows that POSS incorporated into silicone rubbers considerably improves their mechanical and thermal properties and reduces their flammability [11]. Liu et al. [12] have found that POSS with various functional groups, such as phenyl-trisilanol, isobutylo-trisilanol, and isobutyl-monosilanol groups, increases the thermal stability of silicone rubber nanocomposites. As a result of the tests performed, it has been shown that room temperature vulcanized silicone rubber (RTV-SR), containing $5 \%$ of tri-silanol-isobutyl POSS, is characterized by the highest thermal stability among the composites tested. Other studies have shown a synergic effect of silica and POSS on the improvement in thermal and mechanical properties of silicone rubber (RTV-SR) [12].

The use of POSS as effective compounds for reducing the flammability of polymers is presented in a review by Zhang and co-workers [9]. From the review of the source literature, it follows that in the past, attempts were undertaken to examine and explain the mechanism of the synergic action of the POSS-phosphorus compounds on the flammability of polypropylene, polylactide, polyester, and epoxide resins or butyl polysuccinate [11,13-18].

Carosio et al. [19] studied the effect of layer by layer assemblies on the thermal and combustion behavior of acrylic fabrics. Bi-layers consisting of APP/POSS pairs have been deposited on acrylic fibers, creating a homogeneous and regular coating able to completely cover the fibers.

Researchers indicated that the thermal degradation in an inert atmosphere, as well as the thermo-oxidation in air of the acrylic fibers, has been significantly modified by the coatings due to their char-former character [19].

Despite the investigations performed, the effect of POSS, especially the POSS-phosphorus compounds system, on the flammability of polymeric materials has not been totally explained.

The present paper describes pioneering studies on the effect of three POSS compounds containing amino groups (AM-POSS), chlorine groups (HA-POSS), and vinyl groups (OL-POSS) on the thermal properties and flammability of high-temperature vulcanized silicone rubber (SR), also taking into account the decomposition kinetics. The effect of the synergism of POSS-MPP action on the flammability of silicone rubber was also examined. Based on the analyses performed by TG, FTIR, 
conical calorimeter and SEM-EDX methods, the mechanism of the flame-retardant action of POSS-MPP was explained.

\section{Experimental}

\subsection{Materials}

The object of study was methylvinylsilicone rubber (SR), made by "Silikony Polskie" (Nowa, Sarzyna, Poland), with a molecular weight of $60-70 \times 10^{4}(\mathrm{~kg} / \mathrm{mol})$ and vinyl group content of $0.05-0.09 \%$. The rubber was cross-linked with the use of bis(2,4-dichlorobenzoil) peroxide from "Silikony Polskie" in a quantity of 0.7 part by wt $/ 100$ parts by wt. of the rubber (Vulcanised silicone rubber signed as SR OP, where OP is organic perioxide).

The following compounds were used as fillers for the rubber blends: melamine polyphosphate MPP from Everkem (Milano, Italy) (Scheme 1), chemical formula of MPP is $\mathrm{C}_{3} \mathrm{H}_{6} \mathrm{~N}_{6}\left(\mathrm{H}_{3} \mathrm{PO}_{4}\right)_{\mathrm{n}}$, and polyhedral oligomeric silsesquioxanes POSS from Hybridplastics (Hattiesburg, USA). The chemical formula of POSS is $\left(\mathrm{RSiO}_{1.5}\right)_{\mathrm{n}}$ where $\mathrm{R}$ is a hydrogen atom or an organic group (Table 1). Please give the manufacture's location.

Table 1. Chemical structure of POSS nanoparticles.

Material




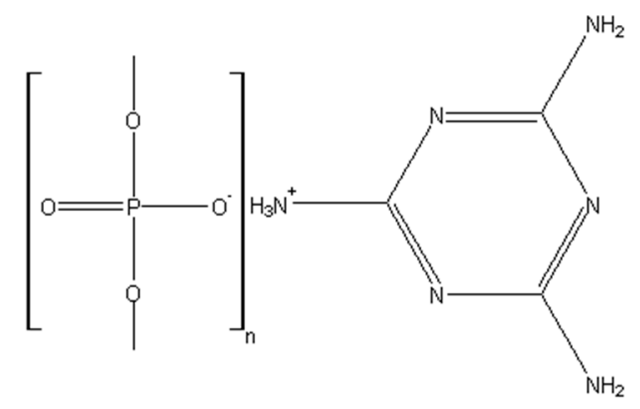

Scheme 1. Melamine polyphosphate structure.

\subsection{Methods}

Preparation of Rubber Blends

Rubber blends were prepared using a laboratory two-roll mill, with roll dimensions of $D=140 \mathrm{~mm}$ and $L=300 \mathrm{~mm}$. The average temperature of the rolls was $35^{\circ} \mathrm{C}$. The rotational speed of the front roll was $V \mathrm{p}=20 \mathrm{rpm}$, friction 1:1.

The composition of the rubber mixtures are shown in Table 2.

Table 2. Composition of the silicone (SR) rubber-based mixtures.

\begin{tabular}{ccccccc}
\hline \multirow{2}{*}{ Sample Description } & \multicolumn{7}{c}{ Component (phr) } \\
\cline { 2 - 7 } & SR & OP & POSS/AM & POSS/HA & POSS/OL & MPP \\
\hline R OP & 100 & 0.7 & 3 & - & - & - \\
SR/AM3 & 100 & 0.7 & - & - & - & - \\
SR/HA3 & 100 & 0.7 & - & 3 & - & - \\
SR/OL3 & 100 & 0.7 & - & - & 3 & - \\
SR/AM6 & 100 & 0.7 & 6 & - & - & - \\
SR/HA6 & 100 & 0.7 & - & 6 & - & - \\
SR/OL6 & 100 & 0.7 & - & - & 6 & - \\
SR/MPP & 100 & 0.7 & - & - & - & 20 \\
SR/AM3/MPP17 & 100 & 0.7 & 3 & - & - & 17 \\
SR/AM6/MPP14 & 100 & 0.7 & 6 & - & - & 14 \\
SR/HA3/MPP17 & 100 & 0.7 & - & 3 & - & 17 \\
SR/HA6/MPP14 & 100 & 0.7 & - & 6 & - & 14 \\
SR/OL3/MPP17 & 100 & 0.7 & - & - & 3 & 17 \\
SR/OL6/MPP14 & 100 & 0.7 & - & - & 6 & 14 \\
\hline
\end{tabular}

SR-silicone rubber; OP-organic peroxide; POSS/AM-Aminopropylisobutyl polyhedral oligomeric silsequioxane; POSS/HA-Chloropropylisobutyl polyhedral oligomeric silsequioxane; POSS/OL_Vinyl polyhedral oligomeric silsequioxane; MPP - melamine polyphosphate.

Kinetic parameters of vulcanization of the elastomer blends were measured by means of MonTech DRPA 300 Rheometer (Buchen, Germany), at $160^{\circ} \mathrm{C}$, according to standard PN-ISO 3417:1994, directly after the preparation of the rubber blends, and for comparison, after a week of conditioning at the ambient temperature. The blends were vulcanized in steel molds placed between electrically heated press shelves.

\subsection{Experimental Techniques}

\subsubsection{FTIR Analysis}

Fourier transform infrared (FTIR) spectra were recorded on a FTIR Spectrum Two spectrophotometer from PerkinElmer (Waltham, MA, USA). Attenuated total reflection (ATR) accessory equipped with a single reflection diamond ATR crystal on ZeSe plate was used for all of the analysis. Measurement parameters were 32 scans from $500-4000 \mathrm{~cm}^{-1}$ in transmittance mode with a resolution of $8 \mathrm{~cm}^{-1}$ and the speed of scanning equal to $0.6329 \mathrm{~cm} \cdot \mathrm{s}^{-1}$. 


\subsubsection{EDS Techniques}

EDS analysis of residue after burning were obtained with the use of scanning electron microscope (SEM), model TM3000 from Hitachi (Krefeld, Germany).

\subsubsection{Thermal Properties}

The thermal properties of the rubber composites were tested under an air atmosphere at a temperature ranging from 25 to $700{ }^{\circ} \mathrm{C}$ with the use of a thermal analyser (Jupiter STA 449F3, Netzsch Company, Selb, Germany). Weighed portions amounted to about 5-10 mg. Investigated samples were analyzed at a heating rate of $10^{\circ} \mathrm{C} / \mathrm{min}$.

Determination of activation energy of destruction studied silicone rubber compositions.

In order to determine the activation energy of destruction, compositions of silicone rubber were tested under a nitrogen atmosphere at temperatures ranging from 25 to $700{ }^{\circ} \mathrm{C}$ with the use of a thermal analyser (Jupiter STA 449F3, Netzsch Company, Selb, Germany). The samples were heated with the rate $5,10,15$, and $20^{\circ} \mathrm{C} / \mathrm{min}$.

In general, the thermal degradation reaction of a solid polymer can be simply shown as: Bsolid $\rightarrow$ Csolid + Dgas, where Bsolid is the starting material, and Dgas and Csolid are the different products during the degradation of Bsolid. In thermogravimetric measurements, the degree of decomposition (conversion) can be calculated as follows [20]:

$$
X=\frac{W_{0}-W_{t}}{W_{0}-W_{f}}
$$

where $X$ is degree of decomposition; $W_{t}, W_{0}, W_{f}$ are the actual, initial, and final mass of the sample, respectively. A typical model for the kinetic process can be expressed as:

$$
\frac{d X}{d t}=k f(X)
$$

where $d x / d t$ is the decomposition rate, $f(X)$, the function of $X$, which depends on the particular decomposition mechanism, and $k$ is the decomposition rate constant, which can be expressed by the Arrhenius equation:

$$
k=A \exp \left(\frac{-E}{R T}\right)
$$

where $A$ is the pre-exponential factor $\left(\mathrm{s}^{-1}\right), E$ is the activation energy $(\mathrm{J} / \mathrm{mol}), R$ is the gas constant $\left(8.314 \mathrm{~J} \cdot \mathrm{mol}^{-1} \cdot \mathrm{K}^{-1}\right)$, and $T$ is the temperature (K). Substituting Equation (3) into Equation (2), gives

$$
\frac{d X}{d t}=A \exp \left(\frac{-E}{R T}\right) f(X)
$$

If the temperature of a sample is changed by a constant value of $\beta(\beta=d T / d t)$, the variation of the degree of decomposition can be analyzed as a function of temperature. Therefore, the reaction rate gives:

$$
\frac{d X}{d T}=\frac{A}{\beta} \exp \left(\frac{-E}{R T}\right) f(X)
$$

Equations (4) and (5) are the basic equations for the kinetic calculation.

This iso-conversional integral method, suggested independently by Flynn and Wall and Ozawa [21,22], uses Doyle's approximation of the temperature integral. This method is based on the equations:

$$
\log \beta=\log \frac{A E}{\operatorname{Rg}(\alpha)}-2.315-\frac{0.457 E}{R T}
$$


where decomposition in $\mathrm{kJ} / \mathrm{mol} ; \alpha$, the degree of conversion; $T$, the absolute temperature to reach the conversion, and is the integral conversion function

$$
g(\alpha)=\int_{0}^{\alpha} \frac{d \alpha}{f(\alpha)}
$$

is the integral conversion function

Thus, at a constant conversion ( $\alpha=$ const.), the plot $\log \beta$ versus $(1 / T)$, obtained from a series experiments performed at several heating rates, should be a straight line whose slope allows for the evaluation of the activation energy:

$$
\text { slope }=\frac{d(\log \beta)}{d(1 / T)}=0.4567\left(\frac{E}{R}\right)
$$

To apply this iso-conversional method, heating rates of $5,10,15$, and $20^{\circ} \mathrm{C} / \mathrm{min}$ were chosen. In this study, the conversion values of $5,15,20,25,30,35,40,45,50,55,60,65$, and $70 \%$ have been used, which would give $\alpha$ values of $0.05,0.15,0.2,0.25,0.3,0.35,0.4,0.45,0.5,0.55,0.6,0.65$, and 0.7 respectively for the Flynn-Wall-Ozawa method.

\subsubsection{Flammability}

The SR composites were examined using a cone calorimeter from Fire Testing Technology Ltd. (East Grinstead, UK). Elastomer samples with dimensions of $(100 \times 100 \pm 1) \mathrm{mm}$ and thickness of $(2 \pm 0.5) \mathrm{mm}$ were tested in a horizontal position with a heat radiant flux density of $35 \mathrm{~kW} \cdot \mathrm{m}^{-2}$. During the tests, the following parameters were recorded: initial sample weight, time to ignition (TTI), sample weight during testing, total heat released (THR), effective combustion heat (EHC), average weight loss rate (MLR), heat release rate (HRR), and final sample weight.

\section{Results}

\subsection{Thermal Properties of Uncured and Cured Silicone Rubber}

The thermal degradation of polysiloxanes (silicone rubbers) can proceed according to three reaction mechanisms: unzipping mechanism, random scission of $\mathrm{Si}-\mathrm{O}$ bond in the main chain of polymer, and external catalytic mechanism.

Polydimethylsiloxanes (PDMS), containing silanol (Si-OH) or hydroxyl-alkyl-silanol ( $\mathrm{Si}-\mathrm{R}-\mathrm{OH})$ terminal groups, undergo thermal degradation according to the unzipping mechanism (Scheme 2) [20,23,24].<smiles>C[Si](C)(C)O[Si](C)(C)O[Si](C)(C)O[Si](C)(C)O[Si](C)(C)O[In][Si](C)(C)O[Si](C)(C)O[Si](C)(C)C</smiles>

Scheme 2. Inter-molecular mechanism degradation of hydroxyl-terminated polysiloxane.

In the first stage of heating, the molecular weight of the polymer violently increases as a result of intermolecular condensation processes proceeding between terminal silanol groups and inter-chain $\mathrm{Si}-\mathrm{O}$ groups. Further increase in temperature causes a linear decrease in the polymer molecular weight as a result of the formation of cyclic siloxanes followed by their tearing off and passing to the gas phase of cyclic siloxanes, mainly trimers and tetramers. Presumably, the cyclic siloxane that is 
stable at the polysiloxane degradation temperature can catalyze the resultant degradation processes of polysiloxane.

The weakest bond in the structure of polydimethylsiloxane (PDMS) is the C-Si bond, whose energy amounts to $326 \mathrm{~kJ} / \mathrm{mol}$. Nevertheless, cyclic siloxanes are formed by the decomposition of a Si-O bond, whose energy value is $451 \mathrm{~kJ} / \mathrm{mol}$, which in turn suggests that the thermal decomposition of PDMS should be considered from the point of view of both kinetic parameters and molecular structure and not only the bond energy.

Polysiloxanes containing terminal groups, such as a trimethylsilyl or vinyl group, as well as accidently occurring vinyl groups in the main chain, undergo thermal degradation by interor intra-molecular reactions proceeding between accidental bonds of the main polymer chains (Scheme 3) [23,25].
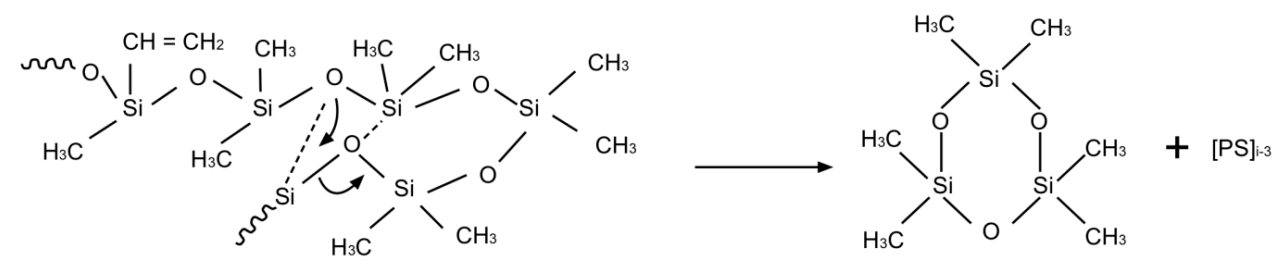

$[P S]$

Scheme 3. Mechanism degradation of polysiloxsane by random scission of Si-O bond.

Unlike the unzipping mechanism, the thermal degradation of polysiloxanes according to the random scission mechanism requires decisively higher temperatures, which causes a violent loss of the sample mass, which is observed already in the early stage of the thermal decomposition of polysiloxane, while the scission of the $\mathrm{Si}-\mathrm{O}$ bond resulting in the formation of oligomeric final products generally occurs in the middle part of polysiloxane chain.

Polysiloxanes containing ionic polar additives or impurities undergo thermal degradation according to a catalytic mechanism. Contrary to the unzipping and random scission mechanisms, the catalytic mechanism consists in hydrolytic decomposing the $\mathrm{Si}-\mathrm{O}$ bond in the main polymer chain. Grassie and Macfarlane have shown that even trace quantities of $\mathrm{KOH}$ dramatically deteriorate the thermal stability of polysiloxanes, even within the range of moderate temperatures [26].

Radhakrishnan [24], investigating the processes of thermal decomposition of polysiloxanes terminated with vinyl group and hydroxyl group, has shown that PDMS terminated with vinyl group is thermally decomposed according to the random scission mechanism, while in the case of PDMS containing hydroxyl terminal groups, a mixed mechanism is noticeable, which means that this polymer is decomposed with the use of terminal hydroxyl groups, according to the unzipping mechanism and the random scission mechanism.

The methylvinylsilicone rubber tested in the atmosphere of a nitrogen gas underwent thermal decomposition in a single stage. The maximal rate of this process at a temperature of $483{ }^{\circ} \mathrm{C}$ amounted to $22.85 \% / \mathrm{min}$ (Figures 1 and 2). Under air, this rubber was thermally decomposed in three stages (Figures 1 and 2). The first stage began at $T=350{ }^{\circ} \mathrm{C}$, while the maximal rate of its decomposition at $T=396{ }^{\circ} \mathrm{C}$ amounted to $3.80 \% / \mathrm{min}$, the second stage began at $\mathrm{T}=410{ }^{\circ} \mathrm{C}$, while its maximal rate at $\mathrm{T}=465^{\circ} \mathrm{C}$ amounted to $16.90 \% / \mathrm{min}$ (third stage). 


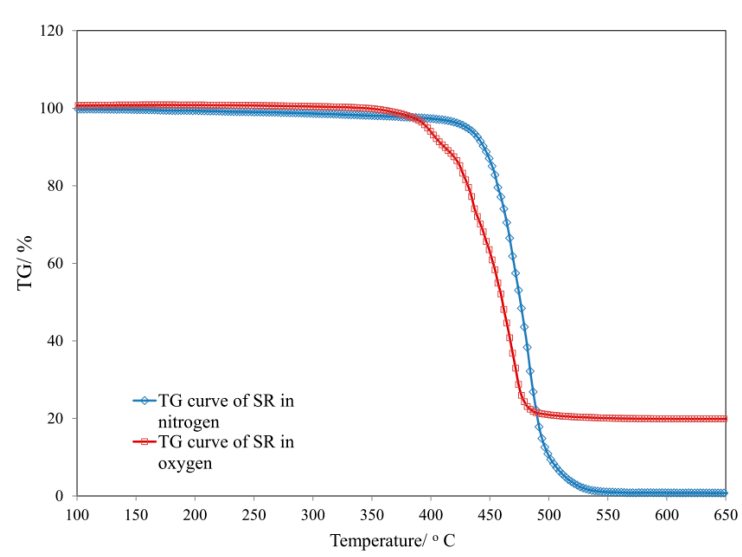

Figure 1. TG curves of silicone rubber in the air and nitrogen atmosphere.

The three-stage decomposition of silicone rubber under air can result from the catalytic action of air in the depolymerization reactions of polysiloxane to volatile cyclic low-molecular compounds, as confirmed by a decisively lower temperature of the beginning of thermal decomposition, TR, of SR rubber under air in relation to the value of TR under neutral gas. The cyclic compounds, formed as a result of the decomposition of SR rubber according to the random scission mechanism, are then thermally decomposed under both air and nitrogen at a temperature above $450{ }^{\circ} \mathrm{C}$.

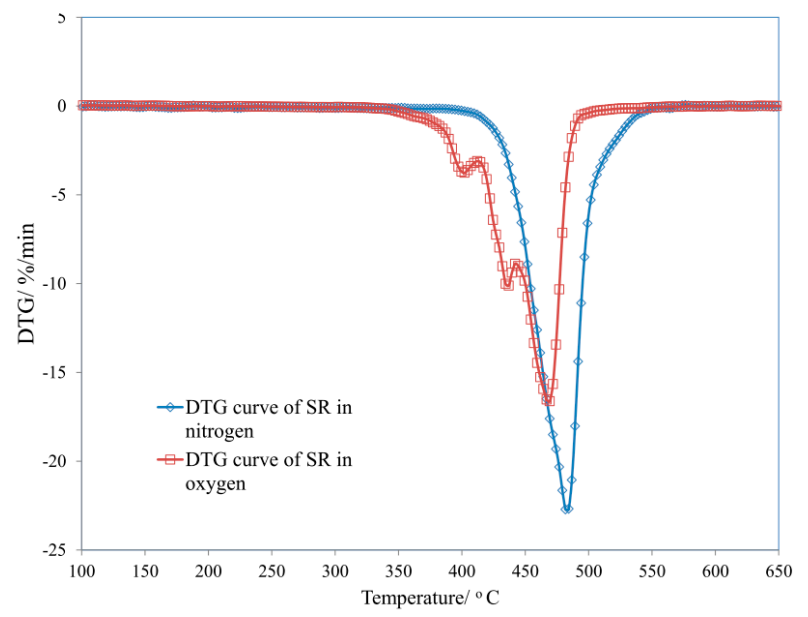

Figure 2. DTG curves of silicone rubber in the air and nitrogen atmosphere.

The cross-linking of the methylvinylsilicone rubber decisively changes the character of its thermal decomposition under air. A small weight loss at $\Delta T$ between 60 and $395^{\circ} \mathrm{C}$ is connected with the presence of plasticizer in the form of low-molecular hydroxydimethylsiloxane, incorporated into the elastomer blend (Scheme 4).

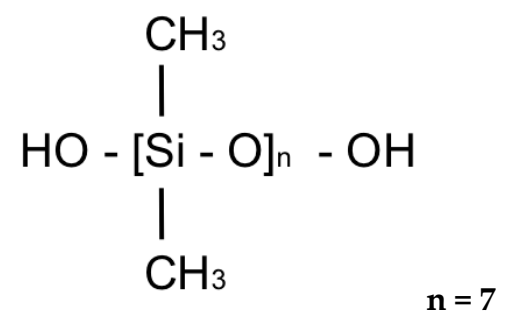

Scheme 4. Structure of low molecular plasticizer. 
The temperature of the beginning of thermal decomposition of cross-linked silicone rubber was increased by $50^{\circ} \mathrm{C}$ in relation to the non-cross-linked rubber. Also, the temperature of the maximal decomposition rate of the cross-linked rubber, amounting to $T_{\mathrm{RMAX}}=505^{\circ} \mathrm{C}$, was increased by $45^{\circ} \mathrm{C}$ in relation to the non-cross-linked rubber.

The cross-linking process of SR rubber also caused a considerable reduction in its thermal decomposition rate. Parameter $d m / d t$ of non-cross-linked rubber amounts to $16.5 \% / \mathrm{min}$, while that of cross-linked rubber is $5.25 \% / \mathrm{min}$. The thermal decomposition residue was also considerably increased, amounting to $5.25 \%$ for the non-cross-linked rubber and 19.95\% for the cross-linked rubber Figures 3 and 4 .

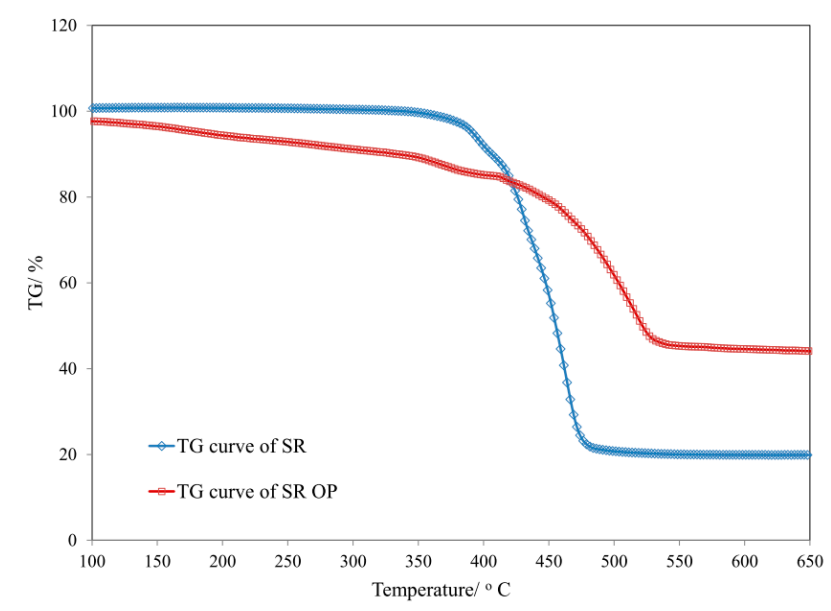

Figure 3. TG curves of uncured (SR) and cured (SR OP) silicone rubber.

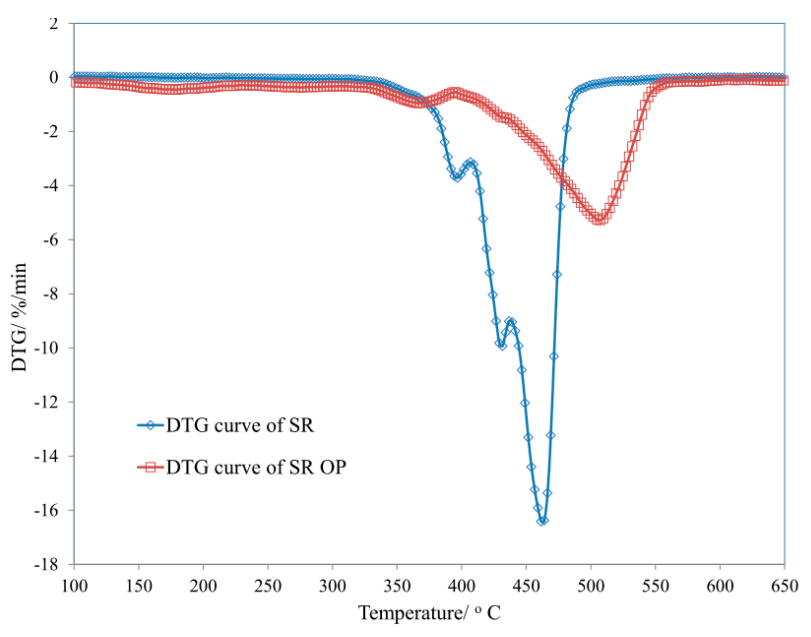

Figure 4. DTG curves of uncured (SR) and cured (SR OP) silicone rubber.

The temperature increase in the decomposition of cross-linked silicone rubber in relation to that of non-cross-linked rubber caused a radical mechanism to predominate in the decomposition of the cross-linked polymethylvinylsiloxane. An increase in temperature caused a hemolytic dissociation of the Si-C bond, which resulted in the formation of macro-radicals whose recombination and cross-linking decrease the elasticity of the polysiloxane chain and consequently impeded further formation of cyclic oligomers.

\subsection{POSS Characteristic}

Figure 5 presents TG and DTG curves of the POSS under investigation. Aminopropylisobutyl silsequioxane (AM-POSS) underwent thermal decomposition in a single stage that began at $T=250{ }^{\circ} \mathrm{C}$. 
The maximal rate of this process at $\mathrm{T}_{\mathrm{RMAX}}=365^{\circ} \mathrm{C}$ amounted to $16.95 \% / \mathrm{min}$. A small residue after thermal decomposition amounting to $5.75 \%$ of the initial sample weight resulted from a great susceptibility of AM-POSS to sublimation processes.

Chloroisobutyl POSS (HA-POSS) underwent a two-stage thermal decomposition. The first principal stage of thermal decomposition with a weight loss at $\Delta T$ between 220 and $420{ }^{\circ} \mathrm{C}$, whose maximal rate at $T=325{ }^{\circ} \mathrm{C}$ amounts to $10.03 \% / \mathrm{min}$, was connected with the detachment of chloroalkyl group, whereas the second stage of thermal decomposition recorded at $\Delta T$ between 450 and $590{ }^{\circ} \mathrm{C}$ was connected with the degradation and decomposition of the cage structure. The residue after the thermal decomposition of HA-POSS amounted to $15.2 \%$, which indicated its lower susceptibility to sublimation than that of AM-POSS.

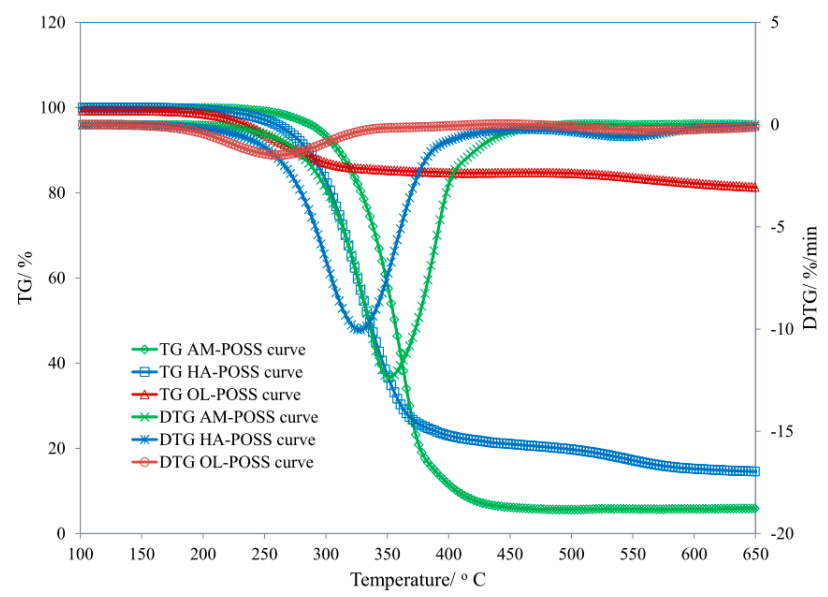

Figure 5. Thermal curves of POSS.

Vinyl POSS (OL-POSS) underwent a four-stage thermal decomposition (Figure 5). The first three decomposition stages, whose maximal rate at $T_{1}=265{ }^{\circ} \mathrm{C}, T_{2}=320{ }^{\circ} \mathrm{C}$, and $T_{3}=375{ }^{\circ} \mathrm{C}$ amounted to $0.79,1.80$, and $0.36 \% / \mathrm{min}$, respectively, were connected with the degradation of unsaturated hydrocarbon chains and the detachment of hydrocarbon destruction products. The fourth stage of thermal decomposition was recorded at $\Delta T=450-650{ }^{\circ} \mathrm{C}$ as in the case of HA-POSS, which was connected with the thermal degradation and decomposition of the cage structure. A very high residue after the thermal decomposition of OL-POSS, amounting to $86.5 \%$ at $T=600{ }^{\circ} \mathrm{C}$, resulted from the susceptibility of this compound to cross-linking and thermal cyclization [27].

FTIR spectra of all studied POSS showed signals at wavenumbers of 745 and $837 \mathrm{~cm}^{-1}$, which were connected with stretching vibrations of the $-\mathrm{CH}$ group. A peak at wavenumber of $1091 \mathrm{~cm}^{-1} \mathrm{was}$ connected with stretching vibrations of $\mathrm{OH}$ group, whereas a signal at wavenumber $1459 \mathrm{~cm}^{-1}$ corresponded to asymmetric stretching vibration of the $-\mathrm{CH}_{3}$ group. The peak at $2952 \mathrm{~cm}^{-1} \mathrm{was}$ attributed to physically connected water at the POSS surface.

Additionally, the FTIR spectrum of POSS/AM showed signals at 1229 and $1570 \mathrm{~cm}^{-1}$, respectively. The first one was connected with valence vibrations, whereas the second was due to deformation vibrations of the $-\mathrm{NH}$ group.

IR spectra of POSS/HA showed a sharp signal at wavenumber $560 \mathrm{~cm}^{-1}$ that is connected with valence vibration of the $\mathrm{C}-\mathrm{Cl}$ group. In the IR spectrum of the POSS/OL, a sharp peak at $548 \mathrm{~cm}^{-1} \mathrm{was}^{-1}$ observed, which was attributed to vibration of the $\mathrm{CH}=\mathrm{CH}_{2}$ group, whereas the signal at $1407 \mathrm{~cm}^{-1}$ corresponded to deformation vibrations of the $-\mathrm{CH}$ group in $-\mathrm{C}=\mathrm{C}-\mathrm{H}$ (Figure 6 ). 


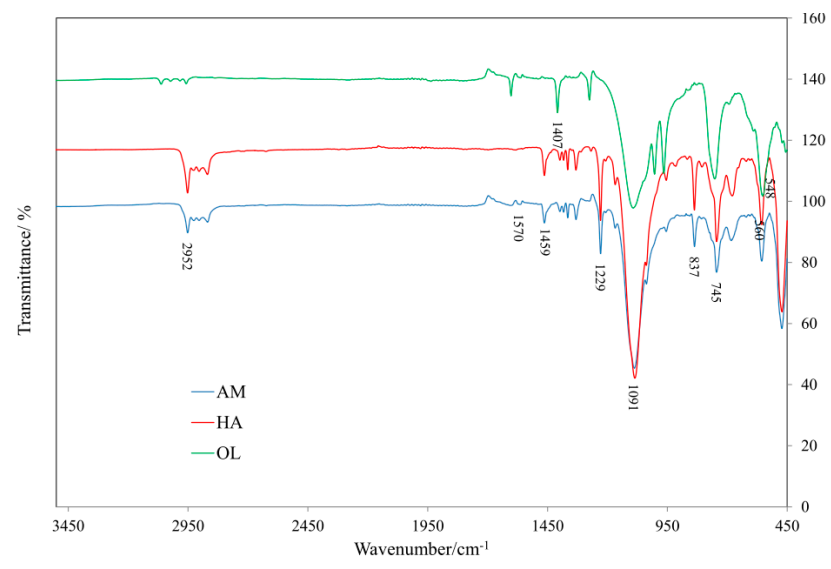

Figure 6. FTIR spectra of studied POSS.

\subsection{IR Analysis of SR Composites}

FTIR spectrum of silicone rubber showed sharp signals at wavenumbers 2963 and $2891 \mathrm{~cm}^{-1}$ that were connected with both the asymmetric and symmetric stretching vibrations of $\mathrm{C}-\mathrm{H}$ group, respectively. Signals at wavenumbers 695, 1415, and $1258 \mathrm{~cm}^{-1}$ were connected with stretching vibrations of the $\mathrm{C}=\mathrm{C}$ and $\mathrm{C}-\mathrm{H}$ groups, and bending stretching derived from $\mathrm{Si}-\mathrm{CH}_{3}$ groups, respectively [28]. Very strong signals at wavenumbers of 1077, 1010, and $787 \mathrm{~cm}^{-1}$ were connected with stretching vibrations of the $\mathrm{Si}-\mathrm{O}-\mathrm{Si}$ group (Figure 7).

The incorporation of silsequioxanes into the silicone rubber matrix did not significantly influence the character of the FTIR spectrum. Taking into account the increase in signal from 1410 to $1420 \mathrm{~cm}^{-1}$, in the case of SR/OL vulcanizate, one should state that the silsequioxanes investigated did not combine with silicone rubber chains during the process of reactive mixing and did not participate in the cross-linking of SR rubber.

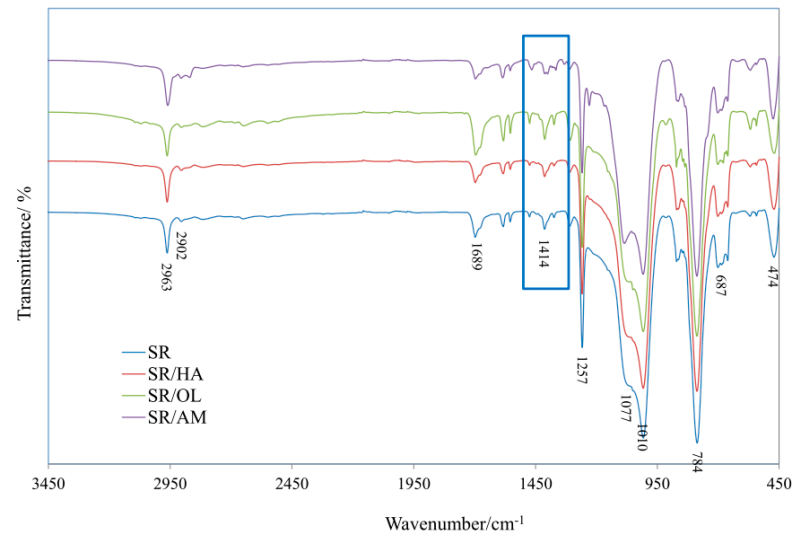

Figure 7. FTIR spectra of SR/POSS composites.

\subsection{Thermal Properties of SR Composites}

The incorporation of polyhedral oligomeric silsequioxanes into the silicone rubber matrix decisively influenced the thermal properties of the rubber, expressed by the temperature of $5 \%$ and $50 \%$ of mass loss $\left(T_{5}\right.$ and $\left.T_{50}\right)$, the thermal decomposition rate of the composite $(\mathrm{dm} / \mathrm{dt})$, the maximal temperature of its thermal decomposition $\left(T_{\text {RMAX }}\right)$, and the residue after its thermal decomposition (Pw) and residue at $T=650{ }^{\circ} \mathrm{C}\left(\mathrm{P}_{650}\right)$ (Table 3).

From the data listed in Table 3, it follows that all the silsequioxanes tested brought about an increase in the value of parameter $T_{5}$. It should, however, be underlined that the highest increase 
in the value of this parameter was recorded for the composites containing OL-POSS. In the case of samples SR/OL3 and SR/OL6, parameter $T_{5}$ was increased by $200{ }^{\circ} \mathrm{C}$ (sample SR/OL3) and by $194{ }^{\circ} \mathrm{C}$ (sample SR/OL6) in relation to the cross-linked SR rubber (Figure 8). These increases confirmed the susceptibility of vinyl silsequioxane to the processes of thermal cross-linking and cyclization.

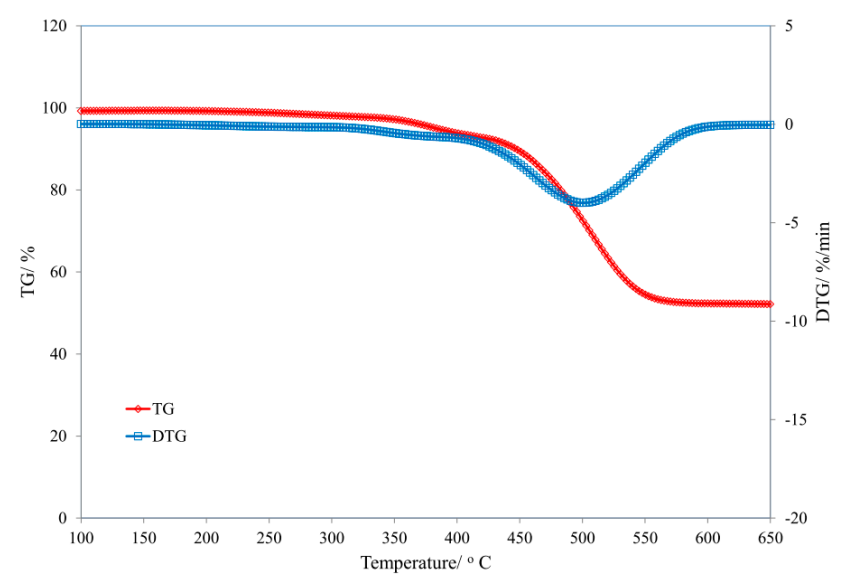

Figure 8. TG and DTG curves of SR/OL3 composite.

Table 3. Thermal properties of SR/POSS composites.

\begin{tabular}{ccccccc}
\hline Sample & $\boldsymbol{T}_{\mathbf{5}}\left({ }^{\circ} \mathbf{C}\right)$ & $\boldsymbol{T}_{\mathbf{5 0}}\left({ }^{\circ} \mathbf{C}\right)$ & $\boldsymbol{d m} / \boldsymbol{d} \boldsymbol{t}(\mathbf{\%} / \mathbf{m i n})$ & $\boldsymbol{T}_{\mathbf{R M A X}}\left({ }^{\circ} \mathbf{C}\right)$ & $\mathbf{P w}(\mathbf{\%})$ & $\mathbf{P}_{\mathbf{6 5 0}}(\mathbf{\%})$ \\
\hline SR & 184 & 520 & 5.25 & 505 & 45.3 & 44.5 \\
SR/AM3 & 320 & - & 4.74 & 520 & 49.0 & 49.5 \\
SR/HA3 & 318 & - & 5.06 & 525 & 51.4 & 51.1 \\
SR/OL3 & 384 & - & 4.87 & 506 & 51.3 & 50.2 \\
SR/AM6 & 337 & 579 & 4.59 & 524 & 53.6 & 51.5 \\
SR/HA6 & 304 & - & 5.40 & 517 & 52.5 & 52.3 \\
SR/OL6 & 378 & - & 3.91 & 514 & 52.3 & 52.4 \\
\hline
\end{tabular}

$T_{5}, T_{50}$-temperature of sample $5 \%$ and $50 \%$ mass loss, respectively; $d m / d t$-maximum rate of thermal decomposition of vulcanizates; $T_{\mathrm{RMAX}}$ - temperature of maximum rate of thermal decomposition of vulcanizates; $\mathrm{Pw}-$ residue after the thermal decomposition of vulcanizates; $\mathrm{P}_{650}$-residue after heating to $T=650{ }^{\circ} \mathrm{C}$.

An important thermal parameter, directly influencing the suppression of the flammability of elastomeric material, is its thermal decomposition rate (parameter $d m / d t$ ). The reduction in the destruction rate of polymeric composites exerts a positive influence on decreasing their flammability. This results from the formation of lower amounts of volatile and flammable products of pyrolysis passing to flame, which inhibits the free radical reactions proceeding in the combustion zone. Among all the samples tested, the lowest value of parameter $d m / d t$ was shown by SR/OL3 and SR/OL6. These samples also showed the highest values of residue after thermal decomposition and at $T=650{ }^{\circ} \mathrm{C}$ (parameter $\mathrm{Pw}$ and $\mathrm{P}_{650}$ ), which distinctly indicated that vinyl groups of POSS/OL, non-active in the process of reactive mixing and rubber vulcanization carried out at $T=130{ }^{\circ} \mathrm{C}$ (Figure 5), took part in the reactions of cross-linking and cyclization proceeding during the thermal decomposition and combustion of SR rubber composites (Table 3).

The values of activation energy of thermal destruction of the SR rubber composites tested (Table 4) confirmed that POSS/OL, from among all the oligomeric silsequioxanes tested, catalyzed the processes of cross-linking and thermal cyclization to the highest extent. 
Table 4. Activation energy values of SR/POSS composites.

\begin{tabular}{cc}
\hline Sample & Ea (kJ/mol) \\
\hline SR & 46.57 \\
SR/AM6 & 51.84 \\
SR/HA6 & 84.17 \\
SR/OL6 & 98.22 \\
\hline
\end{tabular}

The incorporation of melamine polyphosphate into the silicone rubber matrix, except for parameter $T_{5}$, distinctly deteriorated its thermal stability. Under the influence of MPP, not only the thermal decomposition rate, $d \mathrm{~m} / d t$, of the composites increased, but also the residue after the thermal decomposition $\mathrm{Pw}$ and the residue at $650{ }^{\circ} \mathrm{C}$ decreased. Furthermore, melamine polyphosphate considerably reduced the cyclization of silicone rubber as confirmed by lower values of parameter $\mathrm{Pw}$ and $\mathrm{P}_{650}$ of SR/MPP composite in relation to the cross-linked SR (Table 5).

From the data listed in Table 5, it follows that composites containing synergic MPP system and silsequioxane were characterized by a higher thermal stability expressed by parameters $T_{5}, d \mathrm{~m} / \mathrm{dt}$, Pw, and $\mathrm{P}_{650}$ than the SR/MPP composite. A definite reduction in the thermal decomposition rate and an increase in the residue after thermal decomposition and at $T=650{ }^{\circ} \mathrm{C}$ of composite resulted from the formation of a ceramic surface layer that effectively blocked the transfer of mass and energy between the sample and flame.

Table 5. Thermal properties of SR/POSS/MPP composites.

\begin{tabular}{ccccccc}
\hline Sample & $\boldsymbol{T}_{\mathbf{5}}\left({ }^{\circ} \mathbf{C}\right)$ & $\boldsymbol{T}_{\mathbf{5 0}}\left({ }^{\circ} \mathbf{C}\right)$ & $\boldsymbol{d m} / \boldsymbol{d t} \mathbf{( \% / m i n})$ & $\mathbf{T}_{\mathbf{R M A X}}\left({ }^{\circ} \mathbf{C}\right)$ & $\left.\mathbf{P w}_{\mathbf{~}} \mathbf{\%}\right)$ & $\mathbf{P}_{\mathbf{6 5 0}}(\mathbf{\%})$ \\
\hline SR & 184 & 520 & 5.25 & 505 & 45.3 & 44.5 \\
SR/MPP & 315 & 420 & 17.65 & 408 & 32.4 & 28.1 \\
SR/AM3/MPP17 & 313 & 424 & 13.32 & 410 & 32.8 & 29.2 \\
SR/AM6/MPP14 & 305 & 435 & 10.71 & 415 & 35.1 & 32.9 \\
SR/HA3/MPP17 & 380 & 418 & 16.16 & 412 & 33.4 & 30.7 \\
SR/HA6/MPP14 & 328 & 435 & 10.08 & 415 & 36.2 & 33.9 \\
SR/OL3/MPP17 & 340 & 421 & 14.81 & 412 & 33.6 & 34.2 \\
SR/OL6/MPP14 & 378 & 440 & 9.89 & 415 & 35.6 & 36.1 \\
\hline
\end{tabular}

The combustion of silicone rubber proceeds in three stages. The first stage is connected with its flameless thermal decomposition, accompanied by the emission of great amounts of gaseous destruction products. The next stage includes their ignition and a slow propagation of flame over the whole sample surface. The final stage of combustion is connected with the glow of combustion residue that assumes a form of a white uneven surface, under which is a brown heterogeneous layer.

The incorporation of polyhedral oligomeric silsequioxanes, POSS, into the silicone rubber matrix does not fundamentally change the mode of its combustion; nevertheless, it considerably reduces its flammability. From the test results listed in Table 6, it distinctly follows that the flammability of cross-linked SR rubber, especially in the presence of 6 parts by wt. of AM-POSS, HA-POSS, and OL-POSS was considerably reduced (Table 6). 
Table 6. Flammability of SR/POSS composites.

\begin{tabular}{|c|c|c|c|c|c|c|c|}
\hline Sample & $\begin{array}{l}\text { TTI } \\
\text { (s) } \pm 5\end{array}$ & $\begin{array}{c}\text { THR } \\
\left(\mathrm{MJ} / \mathrm{m}^{2}\right) \pm 1\end{array}$ & $\begin{array}{c}\text { HRR } \\
\left(\mathrm{Kw} / \mathrm{m}^{2}\right) \pm 2\end{array}$ & $\begin{array}{c}\text { HRR }_{\mathrm{MAX}} \\
\left(\mathrm{kW} / \mathrm{m}^{2}\right) \pm 2\end{array}$ & $\begin{array}{c}\text { EHC } \\
(\mathrm{MJ} / \mathrm{kg}) \pm 2\end{array}$ & $\begin{array}{c}\mathrm{EHC}_{\mathrm{MAX}} \\
(\mathrm{MJ} / \mathrm{kg}) \pm 1\end{array}$ & $\begin{array}{c}\text { MLR } \\
\left(\mathrm{g} \cdot \mathrm{m}^{-2} \cdot \mathrm{s}^{-1}\right) \pm 0.01\end{array}$ \\
\hline SR & 93 & 21.6 & 73.62 & 124.73 & 37.22 & 79.82 & 0.064 \\
\hline SR/AM3 & 91 & 18.1 & 59.81 & 102.67 & 38.88 & 77.80 & 0.049 \\
\hline SR/HA3 & 80 & 20.3 & 73.59 & 120.26 & 36.50 & 61.50 & 0.051 \\
\hline SR/OL3 & 85 & 19.3 & 62.49 & 105.50 & 34.41 & 76.49 & 0.061 \\
\hline SR/AM6 & 114 & 14.1 & 52.81 & 88.72 & 30.49 & 61.44 & 0.057 \\
\hline SR/HA6 & 106 & 20.7 & 60.58 & 106.45 & 38.1 & 77.42 & 0.050 \\
\hline SR/OL6 & 99 & 13.5 & 38.72 & 66.10 & 31.72 & 78.05 & 0.036 \\
\hline
\end{tabular}

TTI-time to ignition; THR—-total heat release; HRR—heat release rate; $\mathrm{HRR}_{\mathrm{MAX}}$-maximal heat release rate; $\mathrm{EHC}$ - effective combustion heat; $\mathrm{EHC}_{\mathrm{MAX}}$ - maximal effective combustion heat; MLR—mass loss rate.

In the presence of AM-POSS, the value the maximal heat release rate (HRR MAX) of SR/AM6 composite was decreased by $28.87 \%$ in relation to the cross-linked SR rubber, while it decreased in the case of HA-POSS by $14.65 \%$, and in the case of OL-POSS by $47 \%$ (Table 6). Lower values of

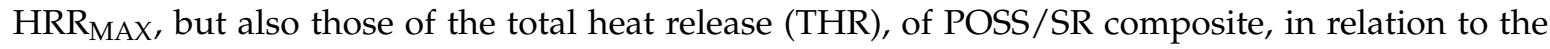
unfilled, cross-linked SR rubber, were connected with the formation of a ceramic coating on the sample surface under combustion (Figures 9 and 10).

It should be distinctly stressed that the silica formed during the thermo-oxidative decomposition of SR rubber, despite its high heat capacity, on account of low cohesion forces between its particles, does not lead to the formation of a homogeneous intumescent boundary layer that would efficiently reduce the effectiveness of fuel diffusion to flame and oxygen to the sample surface [1,29].

From the literature review and the test performed, it clearly follows that only in the presence of POSS, the boundary layer formed during the decomposition of silicone composites assumes a form of uniform ceramic coating that effectively reduces the mass and energy flow between sample and flame $[11,23]$.

EDS analyses indicated that in the presence of POSS, the content of silicon increased with a simultaneous decrease in the oxygen content in the combustion residue of POSS/SR composites (Table 7).

Table 7. EDS results residue after burning.

\begin{tabular}{ccccc}
\hline Sample & C\% & Si\% & O\% & P\% \\
\hline SR & -1 & 51.60 & 48.40 & - \\
SR/AM6 & -1 & 53.87 & 46.13 & - \\
SR/HA6 & -1 & 54.96 & 45.04 & - \\
SR/OL6 & -1 & 55.64 & 44.36 & - \\
SR/MPP & 10.00 & 38.27 & 49.94 & 1.79 \\
SR/AM6/MPP14 & 9.59 & 40.90 & 48.40 & 1.11 \\
SR/HA6/MPP14 & 4.48 & 42.45 & 51.01 & 2.06 \\
SR/OL6/MPP14 & 3.00 & 45.36 & 49.37 & 2.27 \\
\hline \multicolumn{5}{c}{ small amount of carbon. }
\end{tabular}

The increase in silicon content confirmed the formation of ceramic structures suppressed in the boundary layer of burning POSS/SR composite, while the decrease in oxygen content in the combustion residue of the composite tested indicated the reduction in oxygen diffusion to the reaction zone and consequently the inhibition of thermo-oxidative processes by the ceramic layer formed during sample combustion.

The highest percentage silicon content with the lowest percentage content of oxygen was found in the combustion residue of SR/OL6 composite. The presence of unsaturated bonds in the cage structure of OL-POSS facilitated the cross-linking of residue after thermal decomposition and consequently the formation of a ceramic layer on its surface. The insulating character of the boundary layer of SR/OL6 composite was also confirmed by the parameter of mass loss rate (MLR), that in the case of the composite tested, was lower by more than $43 \%$ in relation to the cross-linked SR rubber (Table 6). 
The effect on the SR/HA composite flammability is also exerted by the chlorine atom present in the HA-POSS structure. Halogens, passing to the gaseous phase of combustion, effectively interrupt the highly energetic radical reactions in both the pre- and flame-zones, consequently decreasing the efficiency of degradation and destruction processes of elastomeric composite [30,31].

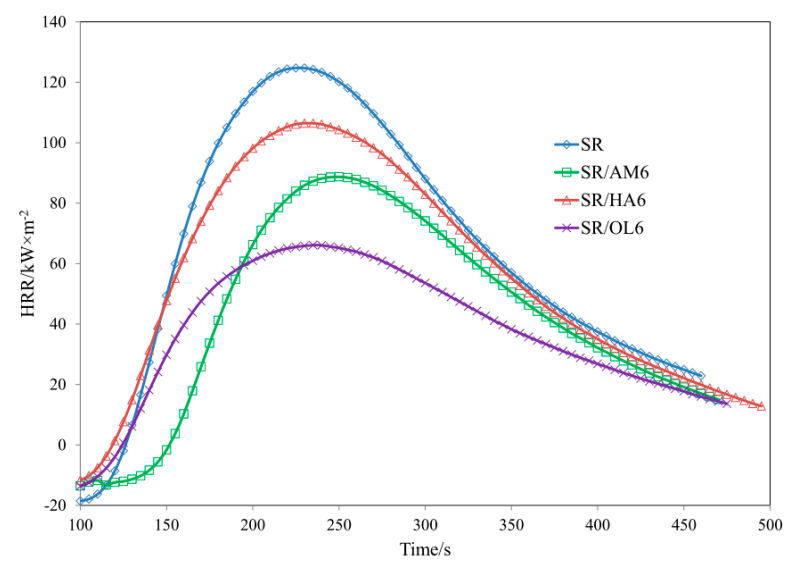

Figure 9. HRR curves of SR/POSS composites.

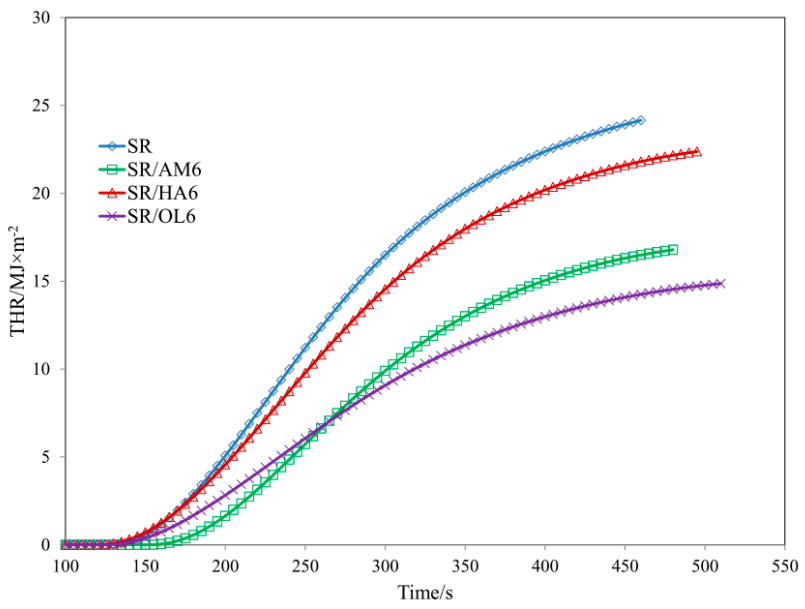

Figure 10. THR curves of SR/POSS composites.

The incorporation of melamine polyphosphate (MPP) to the silicone rubber matrix caused an

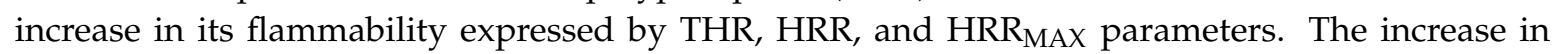
the flammability of cross-linked silicone rubber in the presence of MPP resulted from two effects. First, the acidic products of the thermal decomposition of melamine polyphosphate incorporated into the silicone rubber matrix initiated the decomposition of the Si-O bond in the polymer main chain. Second, MPP, increasing the distances between polymeric chains, considerably reduced the thermal crosslinking process, especially the cyclization of SR rubber as confirmed by both the violent increase in the value of parameter MLR (Table 8) and the rate of thermal decomposition rate, $d \mathrm{~m} / \mathrm{dt}$, with a simultaneous reduction in parameter $T_{50}$ (Table 5 ). It should be distinctly underlined that the flame-retardant effectiveness of polyphosphates compounds reducing flammability directly depended on the availability of a carbon source, either in the form of an organic polymer or a carbonizing additive, such as pentaerythritol. The incorporation of MPP into the matrix of the poor in carbon SR rubber caused the acidic compounds, formed by the decomposition of melamine polyphosphate, to catalyze the decomposition of silicone rubber, practically decreasing the quantity of the homogeneous layer, insulating the carbon residue after the decomposition of SR rubber. 
From the data listed in Table 8, it follows that MPP in combination with POSS reduced the flammability of silicone rubber (Table 8, Figures 11 and 12).

Table 8. Flammability composites of SR/POSS/MPP.

\begin{tabular}{|c|c|c|c|c|c|c|c|}
\hline Sample & $\begin{array}{l}\text { TTI } \\
\text { (s) }\end{array}$ & $\begin{array}{c}\text { THR } \\
\left(\mathrm{MJ} / \mathrm{m}^{2}\right) \pm 1\end{array}$ & $\begin{array}{c}\text { HRR } \\
\left(\mathrm{Kw} / \mathrm{m}^{2}\right) \pm 2\end{array}$ & $\begin{array}{c}\text { HRR }_{\text {MAX }} \\
\left(\mathrm{kW} / \mathrm{m}^{2}\right) \pm 2\end{array}$ & $\begin{array}{c}\text { EHC } \\
(\mathrm{MJ} / \mathrm{kg}) \pm 2\end{array}$ & $\begin{array}{c}\mathrm{EHC}_{\text {MAX }} \\
(\mathrm{MJ} / \mathrm{kg}) \pm 1\end{array}$ & $\begin{array}{c}\text { MLR } \\
\left(\mathrm{g} \cdot \mathrm{m}^{-2} \cdot \mathrm{s}^{-1}\right) \pm 0.01\end{array}$ \\
\hline $\mathrm{SR} / \mathrm{MPP}$ & 56 & 24.5 & 74.04 & 141.48 & 27.95 & 79.13 & 0.120 \\
\hline SR/AM3/MPP17 & 56 & 14.2 & 42.18 & 78.25 & 29.49 & 60.33 & 0.052 \\
\hline SR/AM6/MPP14 & 63 & 7.9 & 30.47 & 55.22 & 13.61 & 59.06 & 0.099 \\
\hline SR/HA3/MPP17 & 54 & 17.4 & 69.75 & 114.42 & 25.31 & 77.38 & 0.092 \\
\hline SR/HA6/MPP14 & 83 & 12.3 & 49.95 & 83.58 & 22.46 & 75.77 & 0.085 \\
\hline SR/OL3/MPP17 & 70 & 11.5 & 29.26 & 50.12 & 21.15 & 73.54 & 0.049 \\
\hline SR/OL6/MPP14 & 72 & 9.2 & 27.52 & 43.63 & 14.24 & 75.85 & 0.059 \\
\hline
\end{tabular}

SR/AM6/MPP 14, SR/HA6/MPP14, and SR/OL6/MPP14 composites were characterized by lower values of parameter $\mathrm{HRR}_{\mathrm{MAx}}$ by $60.83,40.72$, and $66.97 \%$, respectively, in relation to the SR/MPP composite. Also, the parameters of mass loss rate (MLR) of SR/AM6/MPP 14, SR/HA6/MPP14, and SR/OL6/MPP14 underwent reduction by 17.5, 29.16, and 50.8\%, respectively, in relation to that of the SR/MPP composite. The flame retardant action of the synergetic POSS/MPP system expressed by parameters HRR MAX, MLR, and THR (Figure 5, Table 8) and EHC (Table 8) resulted from the formation of a ceramic boundary layer that reduced the diffusion of oxygen to the boundary layer and decreased the intensity of degradation and thermal destruction processes of the composite, as well as constituted a barrier for the mass transport, and reduced the quantity of fuel passing to flame (Table 8) [32].

A lower flammability of SR/POSS/MPP composites in relation to that of SR/POSS resulted from the synergetic action of MPP and POSS during the formation of an insulating boundary layer during the thermal decomposition and combustion of SR/POSS/MPP composites.

The acidic destruction products of melamine polyphosphate initiate the degradation and thermal destruction processes of silicone rubber, which results in the formation of very high quantities of solid carbon products that pass to the flame zone, constituting an additional source of fuel (Parameter HRR MAX, MLR, SR/MPP composite) [33]. The ceramic structure formed in the presence of POSS, making it impossible to transfer carbon destruction products to flame, contributes to their cross-linking and cyclization, and consequently to increase the insulation capacity of the boundary layer formed during the decomposition and combustion of SR/POSS/MPP composites.

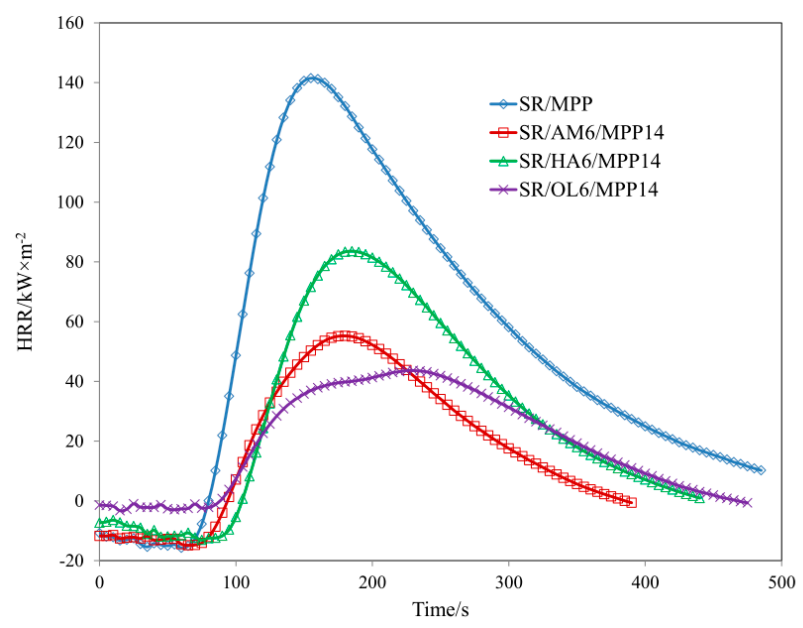

Figure 11. HRR curves composites of SR/POSS/MPP. 


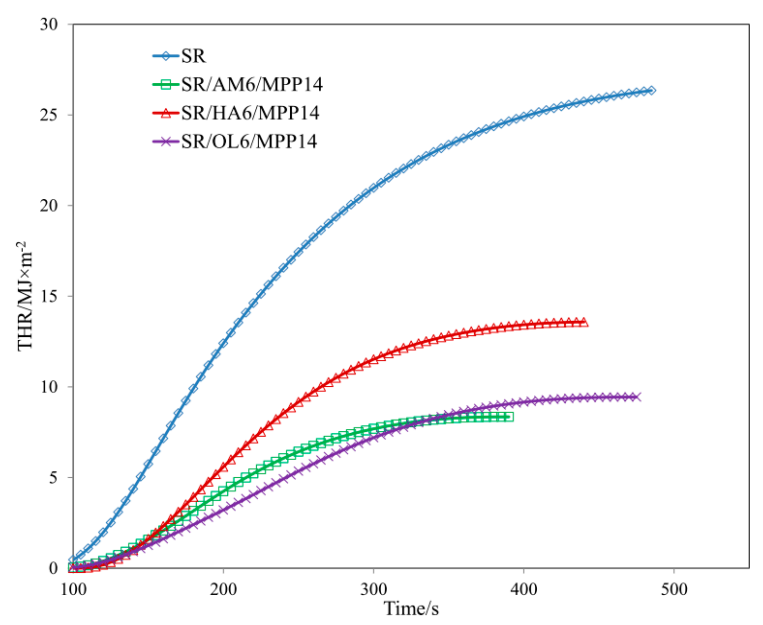

Figure 12. THR curves composites of SR/POSS/MPP.

\section{Conclusions}

This paper presented flame retardant compounds for silicone rubber in the form of polyhedral oligomeric silsequioxanes (POSS), containing both isobutyl groups and amino-propyl (AM-POSS) or chloro-propyl group (HA-POSS) or vinyl groups (OL-POSS). Silsequioxanes were incorporated into the silicone rubber matrix in a quantity of 3 and 6 parts by wt. by the method of reactive stirring with the use of a laboratory mixing mill.

Based on the obtained results, it was found that the studied POSS, non-active in the process of reactive mixing and rubber vulcanization carried out at $T=130{ }^{\circ} \mathrm{C}$, took part in the reactions of cross-linking and cyclization proceeding during the thermal decomposition and combustion of SR rubber composites.

Vinyl POSS, among all the polyhedral oligomeric silsequioxanes tested, catalyzed the processes of cross-linking and thermal cyclization of silicone rubber.

Based on the SEM-EDX analysis, it was found that the decrease of flammability of silicone rubber in the presence of POSS was connected with the formation, during thermal decomposition of POSS/SR composites, of a ceramic coating that limited flow mass and energy between sample and flame.

The increase in the flammability of cross-linked silicone rubber in the presence of MPP resulted from two effects. First, the acidic products of the thermal decomposition of melamine polyphosphate incorporated into the silicone rubber matrix initiated the decomposition of the $\mathrm{Si}-\mathrm{O}$ bond in the polymer main chain. Second, MPP, increasing the distances between polymeric chains, considerably reduced the thermal crosslinking process, especially the cyclization of SR rubber.

A lower flammability of SR/POSS/MPP composites in relation to that of SR/POSS resulted from the synergetic action of MPP and POSS during the formation of an insulating boundary layer during the thermal decomposition and combustion of SR/POSS/MPP composites.

The acidic destruction products of melamine polyphosphate initiated the degradation and thermal destruction processes of silicone rubber, which resulted in the formation of very high quantities of solid carbon products passing to the flame zone, which constituted an additional source of fuel. The ceramic structure formed in the presence of POSS, making it impossible to transfer carbon destruction products to flame, contributed to their cross-linking and cyclization, and consequently to increasing the insulation capacity of the boundary layer formed during the decomposition and combustion of SR/POSS/MPP composites.

Author Contributions: P.R., B.S., D.B. and W.Ż. conceived and designed the experiments. P.R. and B.S. contributed the thermal, cone calorimetry and FTIR analysis. D.B. and W.Ż. contributed SEM-EDX analysis. P.R. wrote the paper.

Funding: This research received no external funding. 
Conflicts of Interest: The authors declare no conflict of interest.

\section{References}

1. Zhu, C.; Deng, C.; Cao, J.-Y.; Wang, Y.-Z. An efficient flame retardant for silicone rubber: Preparation and application. Polym. Degrad. Stab. 2015, 121, 42-50. [CrossRef]

2. Rybiński, P.; Żukowski, W.; Bradło, D. Effect of cenospheric fillers on the flammability and fire hazard of silicone rubber composites. J. Therm. Anal. Calorim. 2016, 125, 1373-1386. [CrossRef]

3. Schartel, B. Phosphorous based flame retardancy mechanism old hat or a starting point for future development. Materials 2010, 3, 4710-4745. [CrossRef] [PubMed]

4. Rybiński, P.; Janowska, G. Influence synergetic effect of halloysite nanotubes and halogen-free flame retardants on properties nitrile rubber composites. Thermochim. Acta 2013, 557, 24-30. [CrossRef]

5. Bar, M.; Alagirusamy, R.; Das, A. Flame retardant polymer composites. Fibers Polym. 2015, 16, $705-717$. [CrossRef]

6. Balaram, P.; Sirohi, S.; Singh, D. Studies on the effects of various flame retardants on polypropylene. Am. J. Polym. Sci. 2013, 3, 63-69. [CrossRef]

7. Rybiński, P.; Syrek, B.; Masłowski, M.; Miedzianowska, J.; Strzelec, K.; Żukowski, W.; Bradło, D. Influence of lignocellulose fillers on properties natural rubber composites. J. Polym. Environ. 2018, 26, 2489-2501. [CrossRef]

8. Dong, F.; Zhao, P.; Dou, R.; Feng, S. Amine-functionalized POSS as cross-linkers of polysiloxane containing $\gamma$-chloropropyl groups for preparing heat-curable silicone rubber. Mater. Chem. Phys. 2018, 208, 19-27. [CrossRef]

9. Zhang, W.; Camino, G.; Yang, R. Polymer/polyhedral oligomeric silsesquioxane (POSS) nanocomposites: An overview of fire retardance. Prog. Polym. Sci. 2017, 67, 77-125. [CrossRef]

10. Kuo, S.-W.; Chang, F.-C. POSS related polymer nanocomposites. Prog. Polym. Sci. 2011, 36, 1649-1696. [CrossRef]

11. Wang, X.; Hu, Y.; Song, L.; Yang, H.; Yu, B.; Kandola, B.; Deli, D. Comparative study on the synergistic effect of POSS and graphene with melamine phosphate on the flame retardance of poly(butylene succinated). Thermochim. Acta 2012, 543, 156-164. [CrossRef]

12. Liu, Y.; Shi, Y.; Zhang, D.; Li, J.; Huang, G. Preparation and thermal degradation behavior of room temperature vulcanized silicone rubber-g-polyhedral oligomeric silsesquioxanes. Polymer 2013, 54, 6140-6149. [CrossRef]

13. Turgot, G.; Dogan, M.; Tayfun, U.; Ozekoc, G. The effect of POSS particles on the flame retardancy of intumescent polypropylene composites and the structure-property relationship. Polym. Degrad. Stab. 2018, 149, 96-111. [CrossRef]

14. Xuan, S.; Hu, Y.; Song, L.; Wang, X.; Yang, H.; Lu, H. Synergistic effect of polyhedral oligomeric silsesquioxane on the flame retardancy and thermal degradation of intumescent flame retardant polylactide. Combust. Sci. Technol. 2012, 184, 459-468. [CrossRef]

15. Song, L.; Xuan, S.; Wang, X.; Hu, Y. Flame retardancy and thermal degradation behaviors of phosphate in combination with POSS in polylactide composites. Thermochim. Acta 2012, 527, 1-7. [CrossRef]

16. Fox, D.M.; Novy, M.; Brown, K.; Murariu, M.; Harris, R.H.; Seppala, J.E.; Gilman, J.W. Flame retarded poly(lactic acid) using POSS-modified cellulose. Effects of intumescing flame retardant formulations on polymer degradation and composite physical properties. Polym. Degrad. Stab. 2014, 106, 54-65. [CrossRef]

17. Chigwada, G.; Jash, P.; Jiang, D.D.; Wilkie, C.A. Fire retardancy of vinyl ester nanocomposites: Synergy with phosphorous-based fire retardants. Polym. Degrad. Stab. 2005, 89, 85-100. [CrossRef]

18. Gerard, C.; Fontaine, G.; Bourbigot, S. Synergistic and antagonistic effects in flame retardancy of an intumescent epoxy resin. Polym. Adv. Technol. 2011, 22, 1085-1090. [CrossRef]

19. Carosio, F; Alongi, J. Influence of layer by layer coatings containing octapropylammonium polyhedral oligomeric silsesquioxane and ammonium polyphosphate on the thermal stability and flammability of acrylic fabrics. J. Anal. Appl. Pyrolysis 2016, 119, 114-123. [CrossRef]

20. Rybiński, P.; Żukowski, W.; Bradło, D. Influence of cenosphere particles on thermal properties composites of silicone rubbers. J. Therm. Anal. Calorim. 2015, 122, 1307-1318. [CrossRef] 
21. Flynn, J.H.; Wall, L.A. A quick, direct method for determination of activation energy from thermogravimetric data. J. Polym. Sci. Polym. Lett. 1966, 4, 323-328. [CrossRef]

22. Ozawa, T.A. New method of analyzing thermogravimetric data. Bull. Chem. Soc. Jpn. 1965, 38, 1881-1886. [CrossRef]

23. Hamdai, S.; Longuest, C.; Perrin, D.; Lopez-Cuesta, J.-M.; Ganachaud, F. Flame retardancy of silicone-based materials. Polym. Degrad. Stab. 2009, 94, 465-495. [CrossRef]

24. Radhakrishnan, T.S. New method for evaluation of kinetic parameters and mechanism of degradation from pyrolysis-GC studies. Thermal degradation of polydimethylsiloxanes. J. Appl. Polym. Sci. 1999, 73, 441-450. [CrossRef]

25. Fang, W.; Zeng, X.; Lai, X.; Li, H.; Chen, W.; Zhang, Y. Thermal degradation mechanism of addition-cure liquid silicone rubber with urea-containing silane. Thermochim. Acta 2015, 605, 28-36. [CrossRef]

26. Grassie, N.; Macfarlane, I.G. The thermal degradation of polysiloxanes-I. Poly(dimethylsiloxane). Eur. Polym. J. 1978, 14, 875-884. [CrossRef]

27. Fina, A.; Tabuani, D.; Carniato, F.; Frache, A.; Boccaleri, E.; Camino, G. Polyhedral oligomeric silsesquioxanes (POSS) thermal degradation. Thermochim. Acta 2006, 440, 36-42. [CrossRef]

28. Chen, D.; Liu, Y.; Huang, C. Synergistic effect between POSS and fumed silica on thermal stabilities and mechanical properties of room temperature vulcanized (RTV) silicone rubbers. Polym. Degrad. Stab. 2012, 97, 308-315. [CrossRef]

29. Hshieh, F.-Y. Shielding effects of silica-ash layer on the combustion of silicones and their possible applications on the fire retardancy of organic polymers. Fire Mater. 1998, 22, 69-76. [CrossRef]

30. Zhang, S.; Horrock, A.R. A review of flame retardant polypropylene fibers. Prog. Polym. Sci. 2003, 28, 1517-1538. [CrossRef]

31. Laoutid, F.; Bonnaud, L.; Alexandre, M.; Lopez-Cuesta, J.-M.; Dubois, P. New prospects in flame retardant polymer materials: From fundamentals to nanocomposites. Mater. Sci. Eng. R 2009, 63, 100-125. [CrossRef]

32. Rybiński, P.; Syrek, B.; Bradło, D.; Żukowski, W.; Anyszka, R.; Imiela, M. Influence of cenospheric fillers on the thermal properties, ceramisation and flammability of nitrile rubber composites. J. Compos. Mater. 2018. [CrossRef]

33. Thirumal, M.; Khastgir, D.; Nando, G.B.; Naik, Y.-P.; Singha, N.K. Halogen-free flame retardant PUF: Effect of melamine compounds on mechanical, thermal and flame retardant properties. Polym. Degrad. Stab. 2010, 95, 1138-1145. [CrossRef] 